\title{
Increasing input power dynamic range of SOA by shifting the transparent wavelength of tunable optical filter
}

\author{
Yu, Jianjun; Jeppesen, Palle
}

Published in:

Journal of Lightwave Technology

Link to article, DOI:

$10.1109 / 50.948279$

Publication date:

2001

Document Version

Publisher's PDF, also known as Version of record

Link back to DTU Orbit

Citation (APA):

Yu, J., \& Jeppesen, P. (2001). Increasing input power dynamic range of SOA by shifting the transparent wavelength of tunable optical filter. Journal of Lightwave Technology, 19(9), 1316-1325.

https://doi.org/10.1109/50.948279

\section{General rights}

Copyright and moral rights for the publications made accessible in the public portal are retained by the authors and/or other copyright owners and it is a condition of accessing publications that users recognise and abide by the legal requirements associated with these rights.

- Users may download and print one copy of any publication from the public portal for the purpose of private study or research.

- You may not further distribute the material or use it for any profit-making activity or commercial gain

- You may freely distribute the URL identifying the publication in the public portal

If you believe that this document breaches copyright please contact us providing details, and we will remove access to the work immediately and investigate your claim. 


\title{
Increasing Input Power Dynamic Range of SOA by Shifting the Transparent Wavelength of Tunable Optical Filter
}

\author{
Jianjun Yu and Palle Jeppesen, Member, IEEE
}

\begin{abstract}
Gain-saturation-induced self-phase modulation (SPM) leading to pulse distortion in a semiconductor optical amplifier (SOA) is overcome by shifting a tunable optical filter (TOF). A recovered or broadened pulse can be obtained after filtering the amplified pulse in the SOA even if the short pulse is only 2-3 ps long. The input power dynamic range (IPDR) can be strongly increased by shifting the TOF and the direction of the shifted transparent wavelength is different for $10 \mathrm{~Gb} / \mathrm{s}$ return-to-zero (RZ) or nonreturn-to-zero (NRZ) signals. The transparent wavelength of the TOF should be shifted to a longer wavelength for RZ signals and to a shorter for NRZ signals. 80-Gb/s optical time division multiplexing (OTDM) signal amplification in the SOA is demonstrated for the first time. We also demonstrate that a large IPDR for the 80-Gb/s OTDM signal can be obtained by shifting the TOF.
\end{abstract}

Index Terms-Gain saturation, input power dynamic range (IPDR), optical time division multiplexing (OTDM), self-phase modulation (SPM), semiconductor optical amplifier (SOA), tunable optical filter (TOF).

\section{INTRODUCTION}

$\mathbf{T}$ HE SEMICONDUCTOR optical amplifier (SOA) is a promising candidate for cascaded optical fiber systems and optical gating because of the coverage of the entire fiber transmission window and the possibilities for integration and low cost [1]-[9]. However, an important issue for the SOA is extinction ratio (ER) degradation due to gain saturation at high input powers, which has a severe impact on the SOA cascadability [1]-[5]. A simple method to improve the ER is to use gain-clamped SOAs (GC-SOAs). GC-SOAs have attracted much interest because they exhibit high saturation input power resulting in superior cascadability for both singleand multiwavelength systems [2]. However, at bit rates of $10 \mathrm{~Gb} / \mathrm{s}$ and beyond, the performance of GC-SOAs is limited by the relaxation frequency causing pulse pattern distortions. Reference [3] reported an optical filtering technique to suppress nonreturn-to-zero (NRZ) waveform distortion by use of a narrow Mach-Zehnder filter of 0.1-nm bandwidth; however, our experiment will show that a narrow filter is not suitable to recover NRZ signals when the SOA has a short carrier lifetime. In this paper, we will demonstrate that shifting the tunable

Manuscript received January 18, 2001; revised May 31, 2001.

J. Yu was with Research Center COM, Technical University of Denmark, Lyngby DK-2800, Denmark. He is now with Agere Systems, Murray Hill, NJ 07974 USA (e-mail: jianjun@agere.com).

P. Jeppesen is with Research Center COM, Technical University of Denmark,

Lyngby DK-2800, Denmark (e-mail: pj@com.dtu.dk).

Publisher Item Identifier S 0733-8724(01)07897-5.

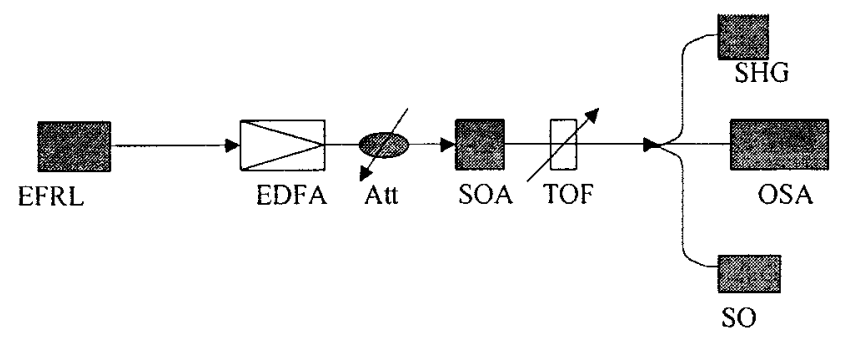

Fig. 1. Experimental setup for $10-\mathrm{GHz}$ optical pulse amplified in an SOA. EFRL: erbium fiber ring laser. SO: sampling oscilloscope. OSA: optical spectrum analyzer. SHG: second-harmonic generation autocorrelator. Att: attenuator. TOF: tunable optical filter. EDFA: erbium-doped fiber amplifier. SOA: semiconductor optical amplifier.

optical filter having a 1.5-nm bandwidth can realize short pulse recovery and input power dynamic range (IPDR) improvement for both 10-Gb/s return-to-zero (RZ) and 10-Gb/s NRZ signals. However, the direction of the shifted transparent wavelength of the tunable optical filter (TOF) is different for RZ and NRZ signals. The TOF transparent wavelength should be shifted to a longer wavelength for RZ signals, but to a shorter one for NRZ signals. SOAs can be used for inline amplification in single or multichannel systems, as well. A number of multichannel or single-channel transmission experiments using SOA amplification have been reported [7]-[9]. However, to our knowledge, no $80-\mathrm{Gb} / \mathrm{s}$ or higher per-channel amplification in SOAs has been reported until now. In this paper, we will demonstrate $80-\mathrm{Gb} / \mathrm{s}$ optical time division multiplexing (OTDM) amplification in the SOA for the first time. In particular, we will demonstrate that IPDR for the $80-\mathrm{Gb} / \mathrm{s}$ OTDM can be improved by shifting the transparent wavelength of the TOF.

\section{II. $10-\mathrm{GHz}$ SHORT PULSES}

The experimental setup is shown in Fig. 1. The short pulse source is a $10-\mathrm{GHz}, 1560-\mathrm{nm}$ erbium fiber ring laser (EFRL) that generates 2.3-ps full-width at half-maximum (FWHM) pulses. The SOA used in the experiment has a total length of $1200 \mu \mathrm{m}$. It has an unsaturated fiber-to-fiber gain of $18 \mathrm{~dB}$ at $130 \mathrm{~mA} \mathrm{[6],} \mathrm{[7].} \mathrm{After} \mathrm{a} \mathrm{TOF} \mathrm{with} \mathrm{a} \mathrm{bandwidth} \mathrm{of} 1.5 \mathrm{~nm}$, the optical pulse is detected by a sampling oscilloscope (SO) with a bandwidth of $32 \mathrm{GHz}$ set by the photodiode, an optical spectrum analyzer (OSA), or a second-harmonic generation (SHG) autocorrelator.

Figs. 2 and 3, respectively, show the waveforms and optical spectra for an input power of $0 \mathrm{dBm}$. Fig. 2(a) shows the op- 


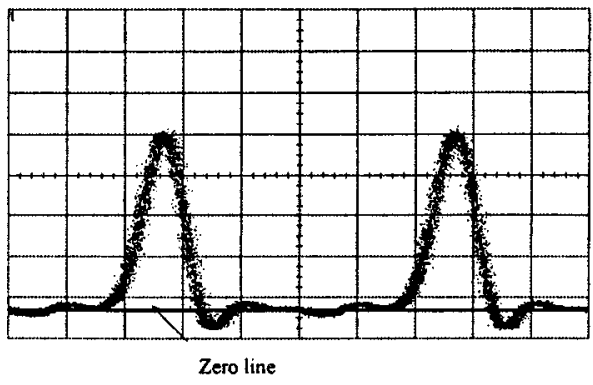

(a)

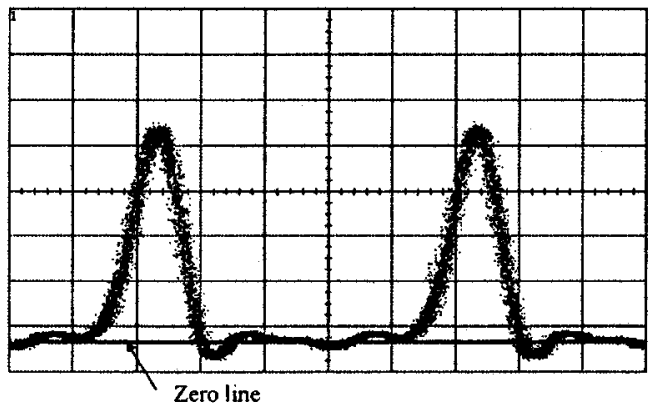

(c)

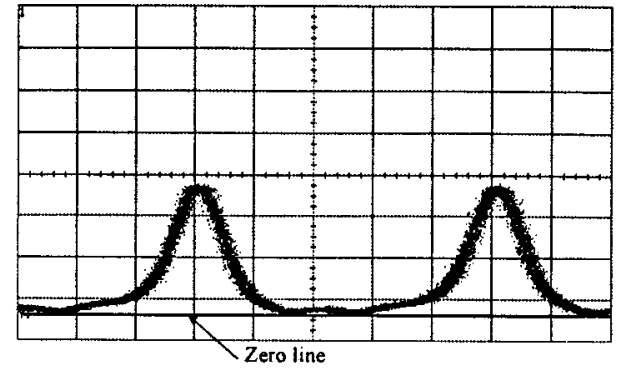

(b)

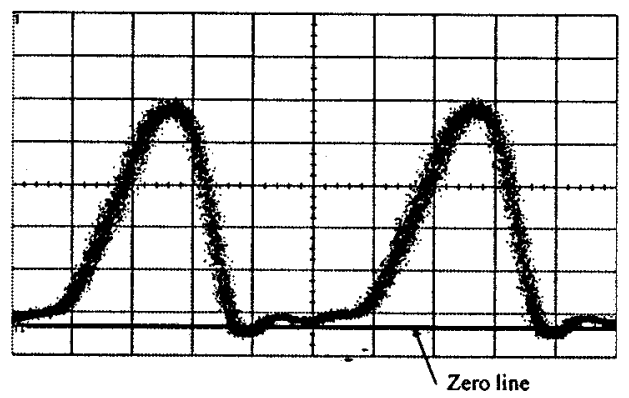

(d)

Fig. 2. Waveforms for 0-dBm input power into the SOA. (a) Input pulse. (b) After the SOA without filter. (c) After shifting the TOF. (d) After fixing the TOF at the input signal wavelength.

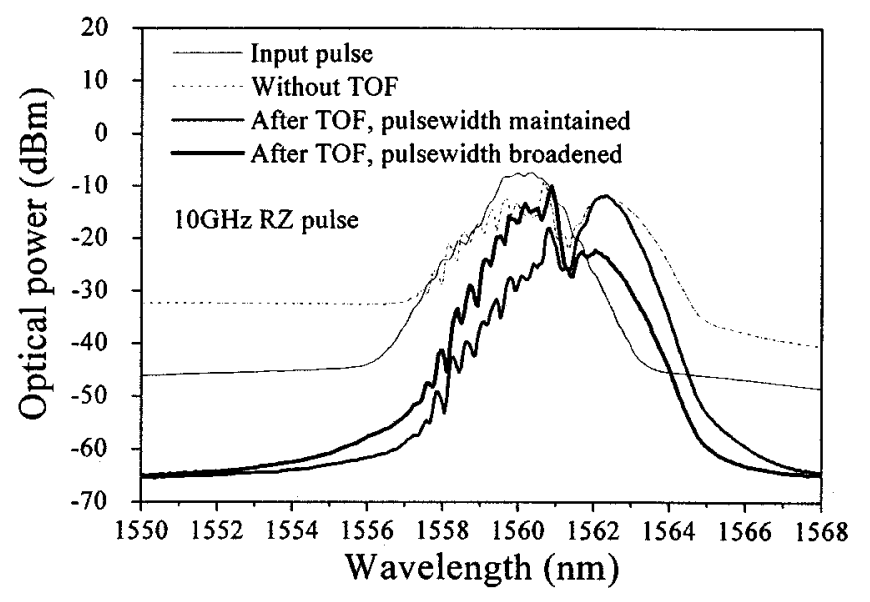

Fig. 3. Optical spectra for 10-GHz optical pulse for 0-dBm input power. Note: Optical power means relative power and resolution is $0.1 \mathrm{~nm}$ in all spectral figures.

tical waveform generated by the EFRL and Fig. 2(b) shows the optical waveform after the SOA without optical filter. Because the leading pulse edge saturates the amplifier, the gain available for the trailing edge is reduced. According to [1], the amplified pulse will become asymmetric such that its leading edge is sharper compared with the trailing edge. However, because of the limited bandwidth of the sampling oscilloscope, Fig. 2(b) does not reveal that the pulse is asymmetric. Due to gain-saturation-induced self-phase modulation (SPM), the pulse spectrum is shifted toward the long-wavelength side (red shift) and the spectrum has developed a multipeak structure [1], which can be seen in Fig. 3. The shifted part of the spectrum toward the long-wavelength side corresponds to the leading edge of the optical pulse and the part of the spectrum corresponding to the trailing edge of the pulse will stay at the position of the input pulse wavelength. If we use a TOF to filter out the spectrum of the leading edge of the pulse, the pulse after the SOA will be recovered. Fig. 2(c) shows the recovered pulse in case of shifting the transparent wavelength of the TOF. The pulsewidth measured by a SHG autocorrelator is $3 \mathrm{ps}$, which is slightly broadened because of the limited bandwidth of the TOF. The time-bandwidth product is 0.324 , which indicates that the output pulse is close to the transform-limited sech pulse. Therefore, the chirp of the output pulse is very small; hence, the pulse is very suitable for transmission in optical fiber. This pulse-maintaining feature is very useful in some situations. For example, when an electroabsorption modulator (EAM) is used to generate a short pulse, an SOA can be used to amplify the pulse to compensate for the large insertion loss of the EAM. However, when the SOA is placed just after the EAM (or it is monolithically integrated), then the optical input power to the SOA becomes relatively high and, consequently, the output waveform becomes strongly distorted by gain saturation [5]. However, if a TOF is added after the SOA, then the pulsewidth can be maintained by shifting the TOF. Fig. 2(d) shows the waveform when the transparent wavelength of the TOF is placed at the wavelength of the input pulse at $1560 \mathrm{~nm}$; the pulsewidth is broadened to approximately $25 \mathrm{ps,}$ mainly determined by the carrier lifetime of the SOA.

\section{III. $10-\mathrm{Gb} / \mathrm{s}$ RZ SIGNALS}

Fig. 4 shows the experimental setup for $10-\mathrm{Gb} / \mathrm{s}$ optical signal amplification in an SOA. In this section, we add an $\mathrm{LiNbO}_{3}$ modulator after the 10-GHz optical pulse source, and by modulating the input pulses with a pseudorandom bit sequence of $2^{31}-1$, an optical RZ signal at $10 \mathrm{~Gb} / \mathrm{s}$ is obtained. After the 


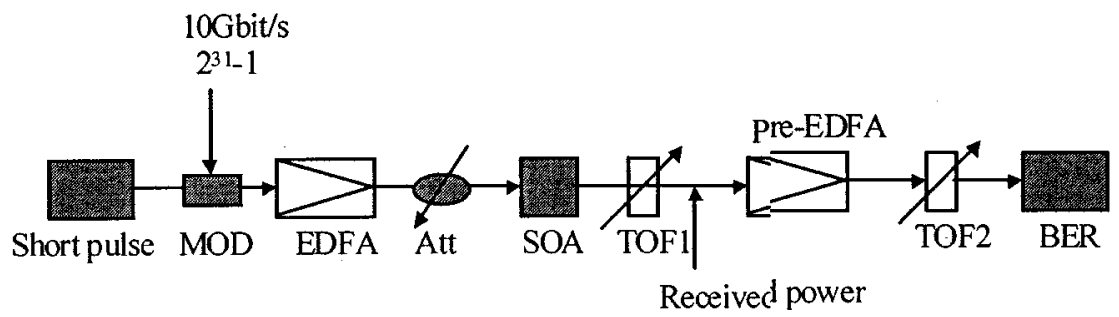

Fig. 4. Experimental setup for $10-\mathrm{Gb} / \mathrm{s} \mathrm{RZ}$ signal amplified in an SOA. BER: bit error rate. $\mathrm{MOD}$ : $\mathrm{LiNbO}_{3}$ modulator.

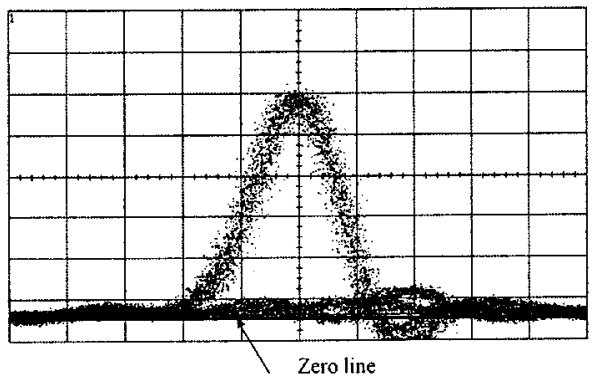

(a)

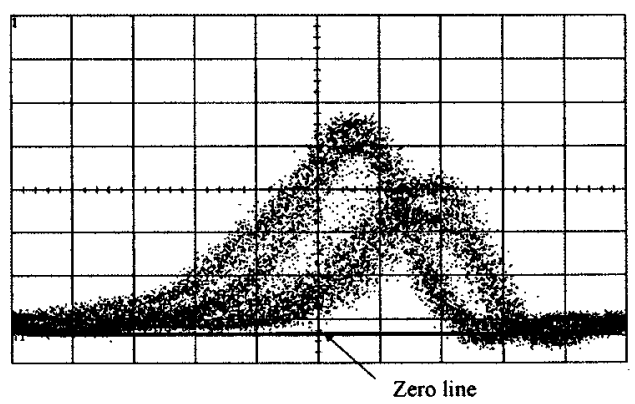

(b)

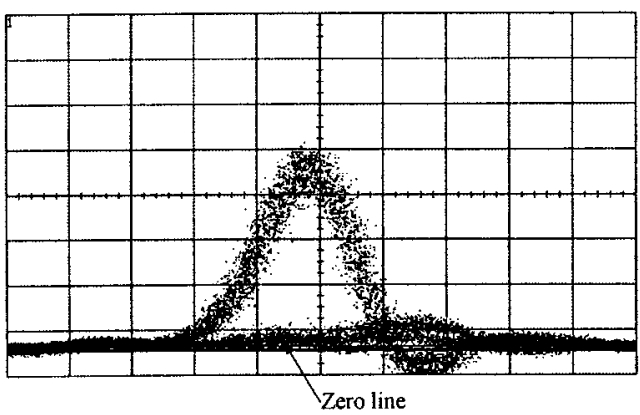

(c)

Fig. 5. Eye diagrams for 0-dBm input power (10 ps/div). (a) Input signal. (b) Without filter. (c) Shifting the TOF.

SOA, the amplified RZ signal is filtered by TOF1, then amplified by a pre-EDFA. After filtering in TOF2, the signal is received by a standard 10-Gb/s NRZ receiver; then, the output signal from the receiver is amplified by a wide-band electrical amplifier (Picosecond Pulse Lab Mod: 5830) and, finally, the bit error rate (BER) is measured. In the following sections, TOF means TOF1.

Fig. 5 shows the eye diagrams for $0-\mathrm{dBm}$ input power. Fig. 5(a) shows the input signal and Fig. 5(b) shows the output

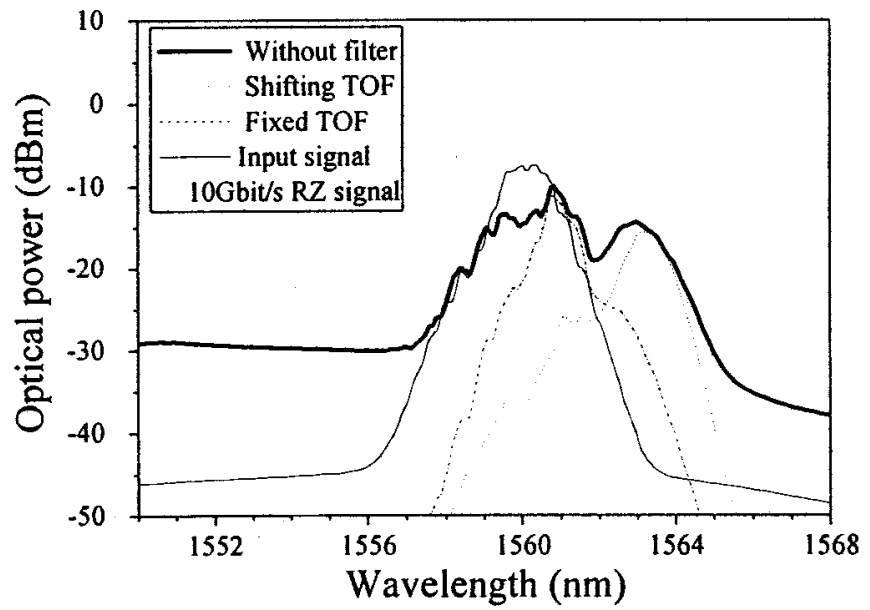

Fig. 6. Optical spectra with input power of $0 \mathrm{dBm}$.

eye diagram without the TOF; we can see that the difference in peak values between " 0 " and " 1 " is very small. Due to gain saturation of the SOA, ER is degraded. Fig. 6 shows the optical spectra. Because gain-saturation-induced SPM shifts the pulse spectrum toward the long-wavelength side (red shift), the optical spectrum develops a multipeak structure. The long-wavelength part of the spectrum corresponds to the leading edge of the "1." This is because the leading pulse edge saturates the SOA and reduces the gain available for the trailing edge. The spectrum of the trailing edge of the " 1 "s and "0"s will not be shifted to the long wavelength region but will remain at the input signal wavelength. After filtering out the leading edge of the optical signal, a good eye diagram is obtained, as shown in Fig. 5(c).

In order to make a more detailed investigation, Fig. 7 shows the waveforms for an input power of $0 \mathrm{dBm}$. We modulate the signal by a PRBS of $2^{7}-1$ because of the trigger limitation of the sampling oscilloscope when measuring waveforms, as opposed to eye diagrams and BER measurement, where $2^{31}-1$ was used, as mentioned earlier. Fig. 7(a) shows that the difference between " 1 "s and " 0 "s after the SOA is very small. We also see that the pattern effect is small because the carrier lifetime of the SOA is smaller than the bit duration time; hence, the carrier density is almost fully recovered when the next " 1 " arrives. Fig. 7(b) shows that the waveform is almost recovered after shifting the TOF. When the TOF transparent wavelength stays at the position of the original input signal, the waveform consists of the components of the amplified " 0 "s and the trailing edge of "1"s of the input signal. Fig. 7(c) shows the trailing edge of " 1 "s and amplified " 0 "s, and the " 1 "s are broadened. 


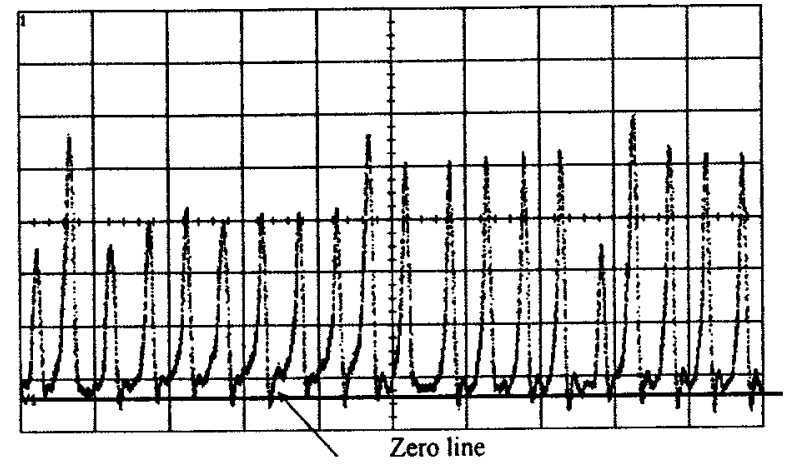

(a)

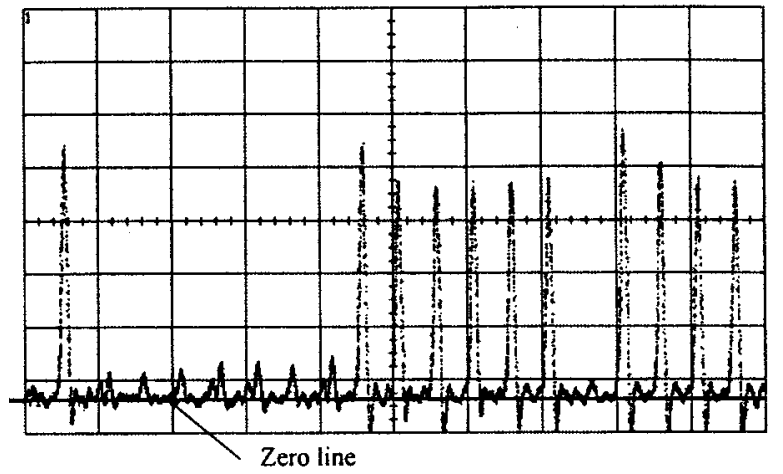

(b)

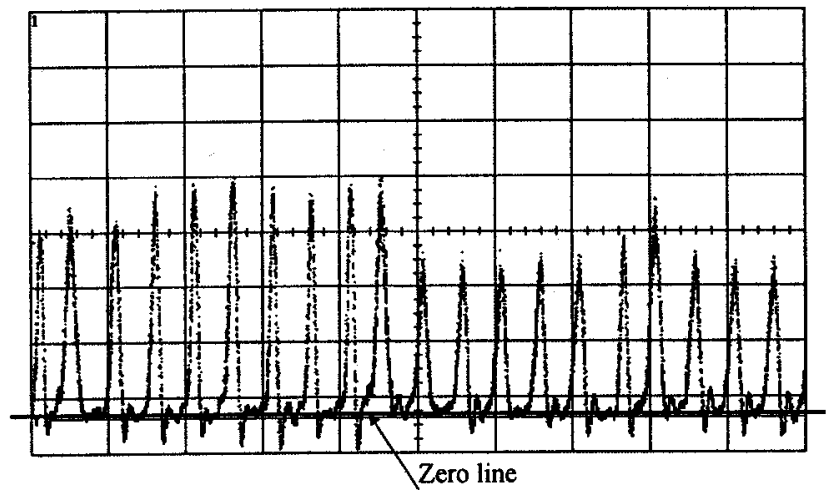

(c)

Fig. 7. Optical waveforms with $0-\mathrm{dBm}$ input power (200 ps/div). (a) Without optical filter. (b) After shifting the TOF. (c) After fixing the TOF at almost the input signal wavelength.

Fig. 8 shows BER performance after shifting the TOF. The penalty at $10^{-9}$ after shifting is very small when the input power is $-15.5 \mathrm{dBm}$; however, the penalty is about $1.2 \mathrm{~dB}$ when the input power is $0 \mathrm{dBm}$ and the penalty is caused by the remaining pattern effect that can be seen in Fig. 7(b).

Fig. 9 shows the optimal transparent wavelength of the TOF as a function of the input power into the SOA. It is clearly seen that the larger the input power is, the longer the center wavelength of the TOF is, as well.

Fig. 10 shows that shifting the TOF is a very effective method to increase IPDR. Fixing the transparent wavelength of the TOF, the IPDR at $2 \mathrm{~dB}$ power penalty is $6 \mathrm{~dB}$. The penalty at low input power is caused by a low signal-to-noise ratio (SNR), whereas the penalty at high input power is caused by ER degradation due to gain saturation. By shifting the TOF, the IPDR is strongly in-

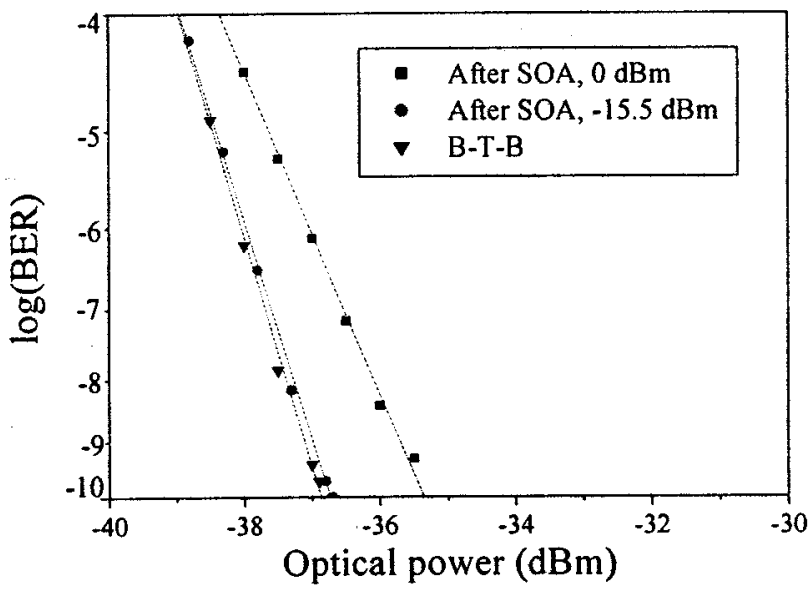

Fig. 8. BER performance.

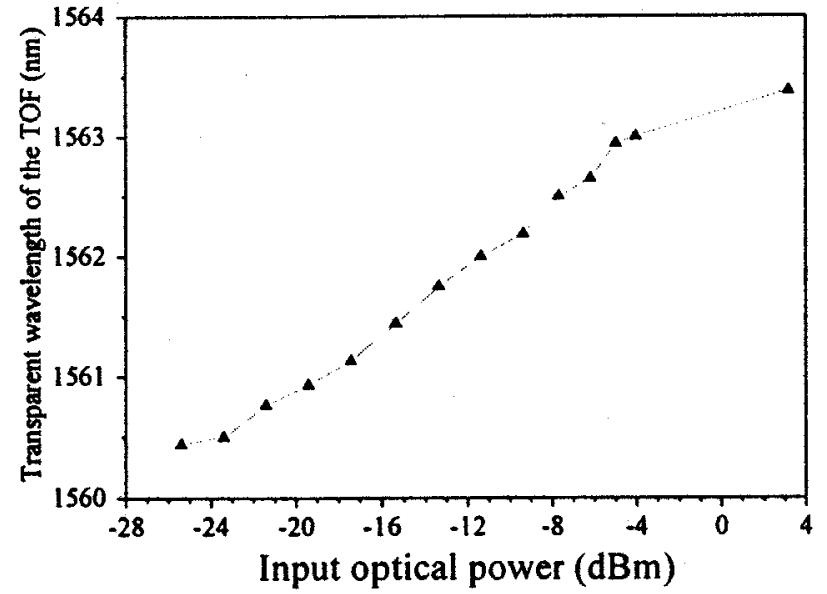

Fig. 9. Shifted wavelength of optical filter as a function of input optical power.

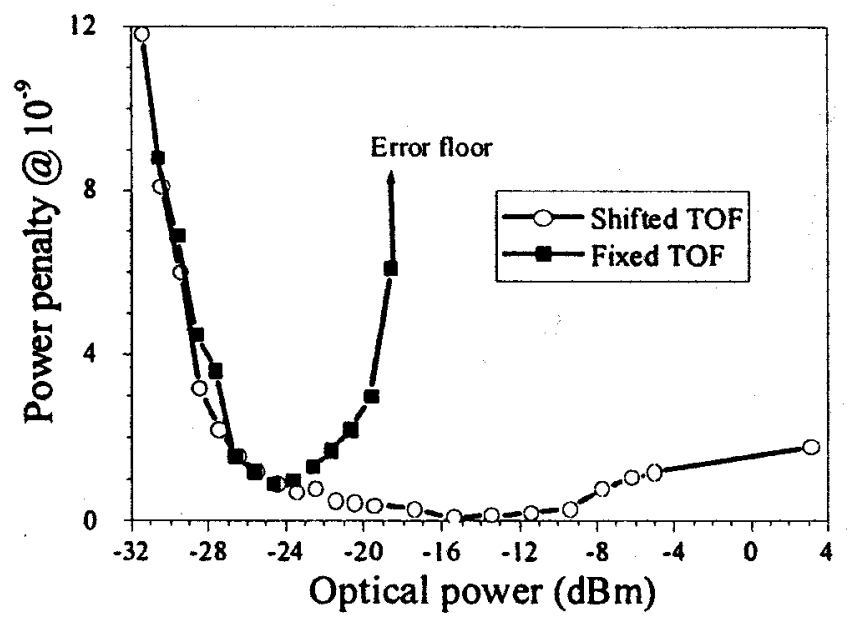

Fig. 10. Power penalty as a function of input power.

creased and the IPDR at $2 \mathrm{~dB}$ penalty is now larger than $32 \mathrm{~dB}$. When the input signal power becomes large enough-for example, larger than $-4 \mathrm{dBm}$ - the penalty is increased; this is due to the fact that the pattern effect after the SOA will be increased and can no longer be eliminated completely by shifting the TOF as done in Fig. 7(b). 


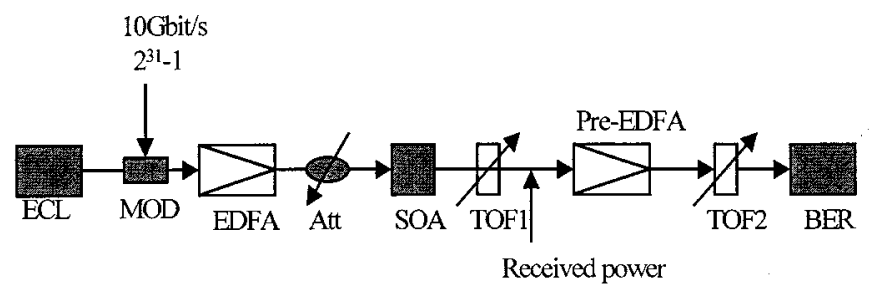

Fig. 11. Experimental setup for 10-Gb/s NRZ signals amplified in the SOA. ECL: external cavity laser.

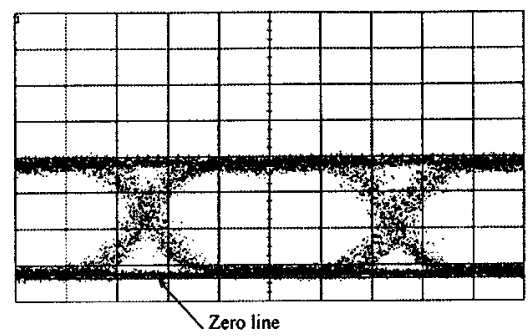

(a)

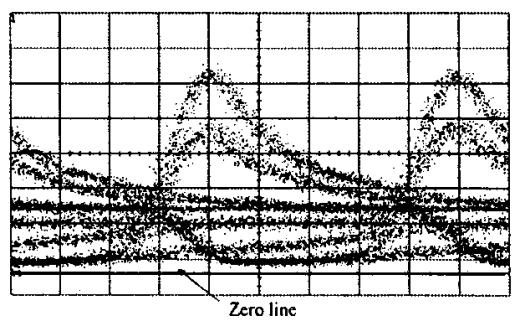

(b)

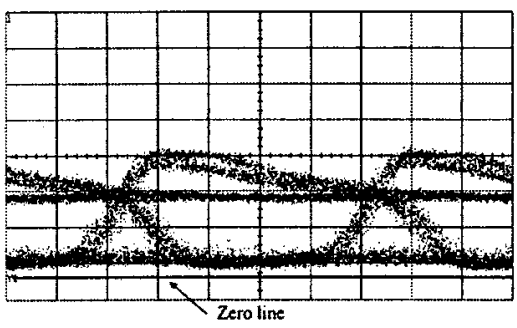

(c)

Fig. 12. Eye diagrams for $-4-\mathrm{dBm}$ input power ( $20 \mathrm{ps} / \mathrm{div})$. (a) Input signal. (b) Without TOF. (c) After shifting the TOF.

\section{IV. $10-\mathrm{Gb} / \mathrm{s}$ NRZ SIGNALS}

Fig. 11 shows the experimental setup for $10-\mathrm{Gb} / \mathrm{s}$ NRZ signals. After the SOA, the amplified NRZ signal is filtered by TOF1, then amplified by a pre-EDFA. After filtering by TOF2, the signal is received by a standard $10-\mathrm{Gb} / \mathrm{s}$ NRZ receiver, and then the BER is measured. In the following sections, TOF again means TOF1.

Fig. 12 shows eye diagrams for an input power of $-4 \mathrm{dBm}$. Because of gain saturation, the signal after the SOA is distorted and has a small ER, as shown in Fig. 12(b). Because the pulsewidth of the NRZ pulse is larger than the carrier lifetime for the SOA, the saturated gain has time to recover during the pulse [1]; therefore, the pattern effect is very pronounced. In the frequency domain, the optical spectrum is broadened to both the red and blue side as shown in Fig. 13(a). Furthermore, the

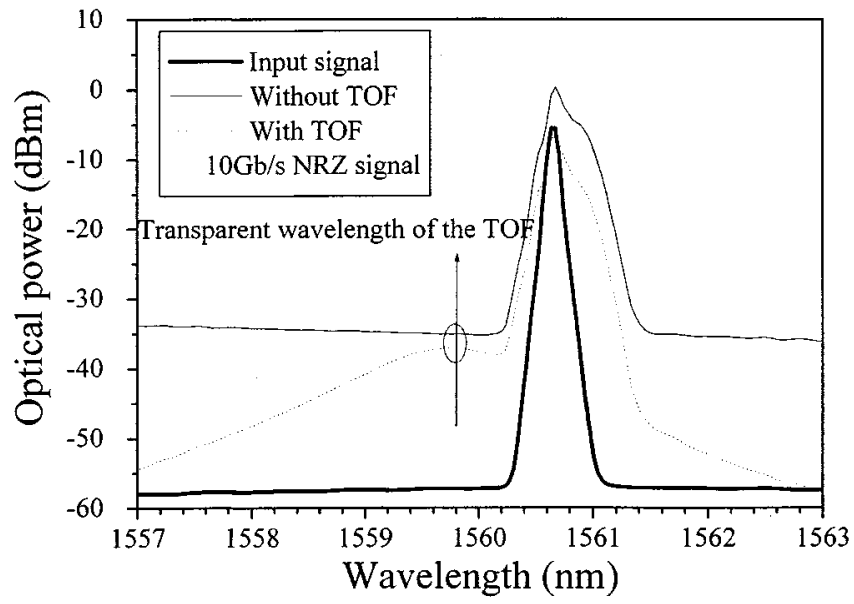

(a)

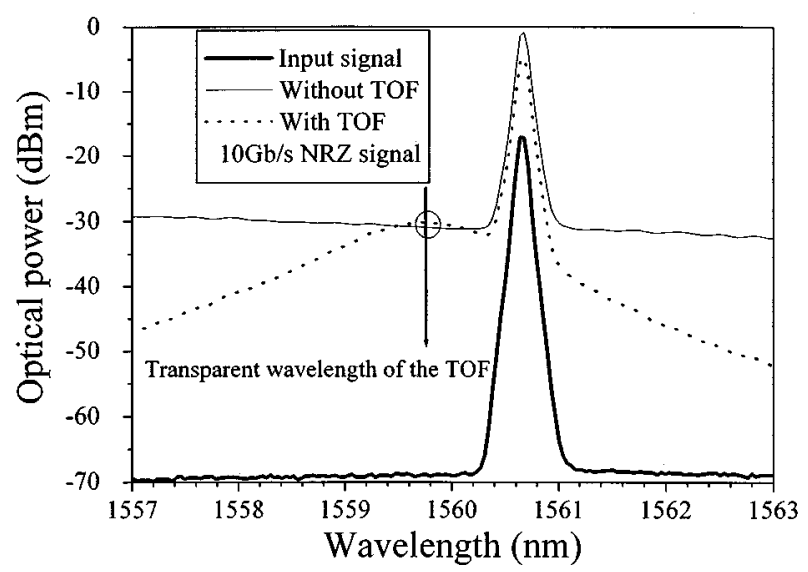

(b)

Fig. 13. Optical spectra for different input powers. (a) $-4 \mathrm{dBm}$. (b) $-15 \mathrm{dBm}$.

red-shifted part of the spectrum is larger than the blue-shifted part, and this is in good agreement with the theoretical prediction in [1]. The TOF is used to reduce the red-shifted part stemming from the gain-saturation-caused SPM; therefore, the transparent wavelength of the TOF is shifted to a shorter wavelength. Fig. 12(c) shows that the pattern effect is reduced and the ER improved after shifting the TOF. Because the transparent wavelength of the TOF is not very far away from the center wavelength of the input signal, and the wavelength of the amplified " 0 "s stays at this center wavelength, the amplified "0"s are not fully suppressed by the TOF; therefore, the ER is not much improved. Because the blue-shifted part of the spectrum caused by SPM cannot be suppressed, the pattern effect is not fully eliminated.

In a further investigation, Fig. 14 shows the waveforms for an input power of $-4 \mathrm{dBm}$. Fig. 14(a) shows the amplified waveform of " $110010101000000011111101 \ldots .$. " We can see that the leading edge of the first " 1 " of the 6 consecutive " 1 "s is amplified most, because the leading edge of the first " 1 " saturates the SOA and reduces the gain available for the following "1"s; this leads to an obvious pattern effect. In the frequency domain, the leading edge of the first " 1 " is shifted to both longer and shorter wavelengths. In order to eliminate the pattern effect, we should suppress simultaneously the red- and blue-shifted frequency components. Fig. 14(b) shows that the pattern effect is 


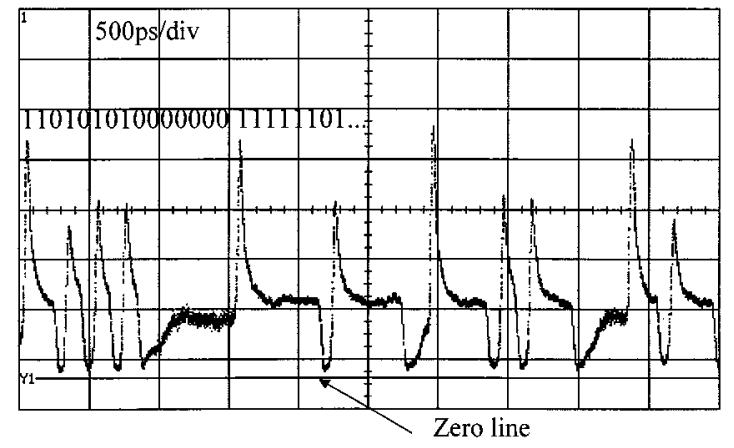

(a)

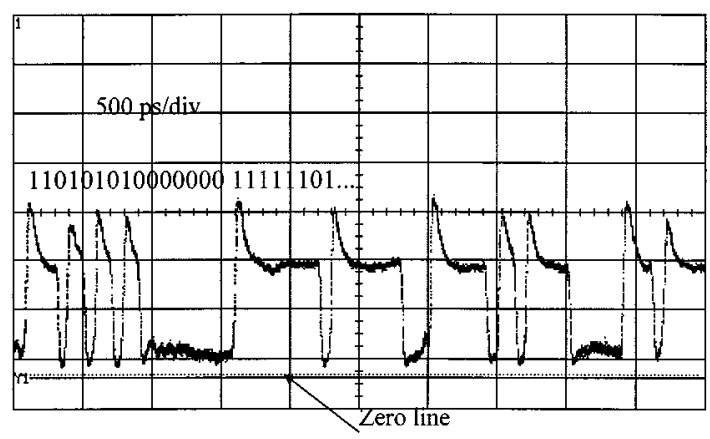

(b)

Fig. 14. Waveform for input power of $-4 \mathrm{dBm}$. (a) Without the TOF. (b) After shifting the TOF.

reduced when the red-shifted frequency components are eliminated by shifting the TOF transparent wavelength to a shorter wavelength, as shown in Fig. 13(a). Fig. 15 shows the eye diagram for an input power of $-15 \mathrm{dBm}$; compared with Fig. 12(b), the pattern effect is reduced because of small gain saturation. After the TOF, a very good eye diagram is obtained. The optical spectrum is shown in Fig. 13(b). Because of small input power, the spectrum broadening caused by gain saturation is very small.

Fig. 16 shows that shifting the TOF is a very effective method to increase IPDR. For unshifted center wavelength of the TOF, the IPDR at 2-dB power penalty is $7.5 \mathrm{~dB}$, and the penalty at low-input power to the SOA is caused by a low SNR. The penalty at high-input power is caused by ER degradation due to gain saturation. After shifting the TOF, the IPDR is strongly increased, and the IPDR at 2-dB penalty is now $16.5 \mathrm{~dB}$. When the input signal power is large enough-for example, larger than $-7 \mathrm{dBm}$ - the penalty is increased; this is due to the fact that the red-shifted part of the spectrum cannot be fully eliminated by the nonperfect optical filter; similarly, the blue-shifted part of the spectrum cannot be eliminated by the TOF, and the amplified " 0 "s cannot be fully suppressed. However, if we could use an additional TOF to suppress also the blue-shifted part of the spectrum, the pattern effect in Fig. 12(c) could be further reduced and the IPDR improved.

In [3], Inoue used a Mach-Zehnder with a bandwidth of $0.1 \mathrm{~nm}$ to recover the distorted NRZ signal. Because the carrier lifetime is longer than the pulsewidth, only the red-shifted part of the spectrum can be seen in this reference, and the distortion after the SOA only occurs in "1"s, not in "0"s. Therefore, after the narrow filter, the red-shifted part can be suppressed and the pattern effect eliminated. However, in our experiment, where

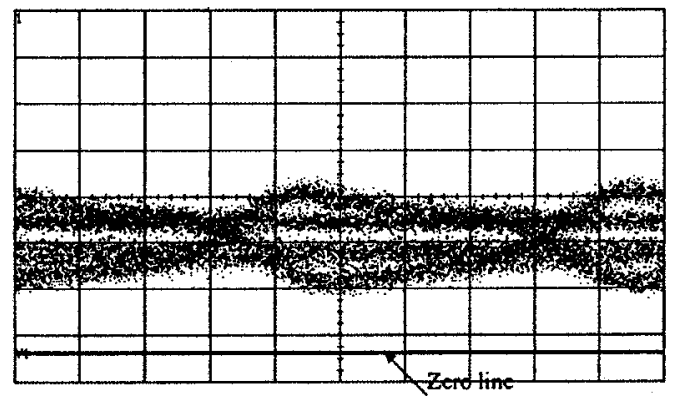

(a)

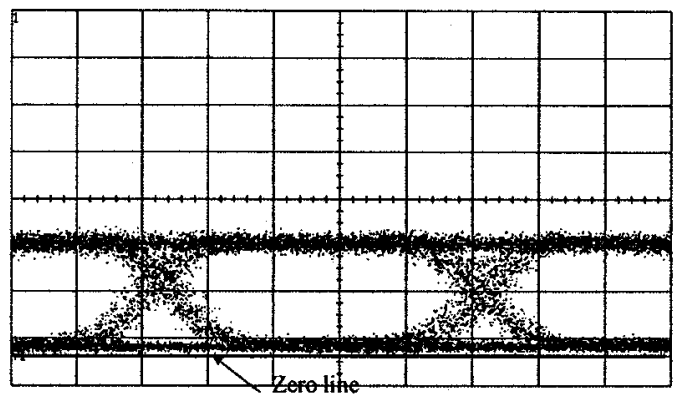

(b)

Fig. 15. Eye diagrams for input power of $-15 \mathrm{dBm}$ (20 ps/div). (a) Without the TOF. (b) After shifting the TOF.

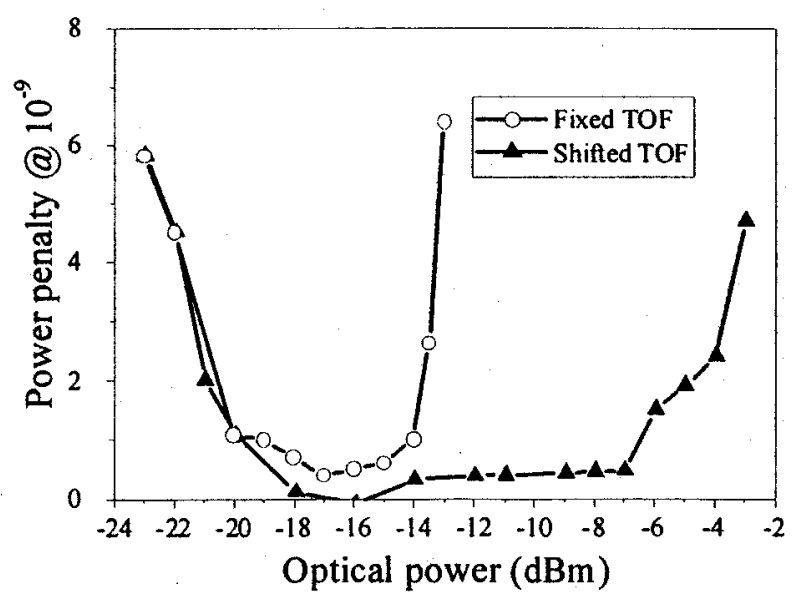

Fig. 16. Power penalty as a function of input power.

the SOA has a short carrier lifetime, the "0"s are also amplified and distorted, as in Fig. 12(b). If we only use a narrow filter to eliminate the red- and blue-shifted part of the spectrum, and the transparent wavelength of the TOF still remains at almost the same wavelength as that of the input signal, as in [3], the distortion of "1"s can be eliminated. However, the center wavelength of the amplified " 0 " stays at the input signal wavelength; therefore, the ER cannot be improved because the distortion of " 0 "s cannot be recovered.

\section{V. $80-\mathrm{Gb} / \mathrm{s}$ OTDM SIGNALS}

The experimental setup is shown in Fig. 17. Two nonlinear optical loop mirrors (NOLMs) are used of which one is used to demultiplex the $80-\mathrm{Gb} / \mathrm{s}$ OTDM signal to $10 \mathrm{~Gb} / \mathrm{s}$ in time domain. Because two narrow pulses are needed for all-optical 


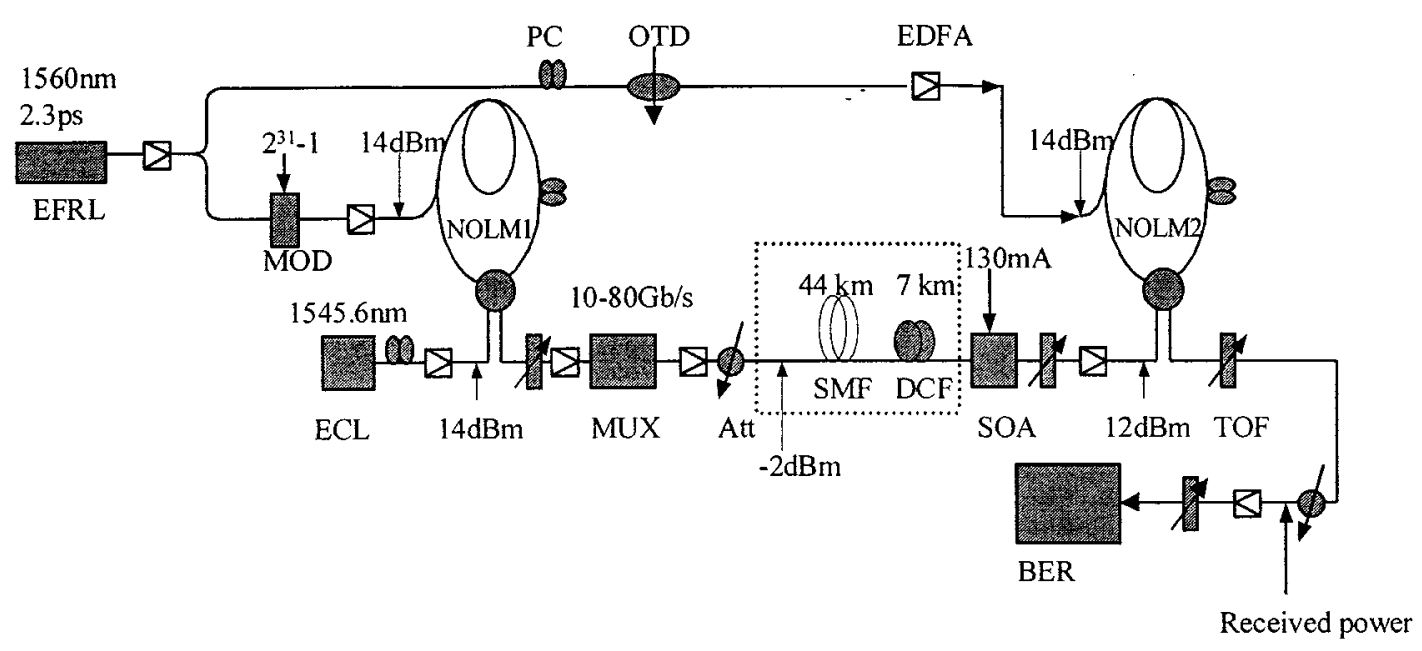

Fig. 17. Experimental setup for 80-Gb/s OTDM signals amplified in the SOA. NOLM: nonlinear optical loop mirror. MUX: multiplexer. OTD: optical time delay, PC: polarization controller.

demultiplexing in NOLM2, but only one short pulse source is available, we use wavelength conversion based on cross-phase modulation in NOLM1 to obtain the narrow pulsewidth signal [10], [11]. The control pulse for the NOLM1 is generated by a $10-\mathrm{GHz}, 1560-\mathrm{nm}$ EFRL, and the FWHM pulsewidth is $2.3 \mathrm{ps}$. After adding the $\mathrm{LiNBO}_{3}$ modulator, and modulating the control pulses with a pseudorandom bit sequence of $2^{31}-1$, a control signal at $10 \mathrm{~Gb} / \mathrm{s}$ is obtained. The continuous wave (CW) lightwave is generated by a tunable external cavity laser. The control signal is coupled into NOLM1 using a wavelength-independent 3-dB optical coupler. The length of the high-nonlinearity dispersion shifted fiber (HNL-DSF) in NOLM1 used for wavelength conversion is $1 \mathrm{~km}$. The zero dispersion wavelength, dispersion slope, and nonlinear coefficient of the HNL-DSF are $1552 \mathrm{~nm}, 0.022 \mathrm{ps} / \mathrm{nm}^{2} / \mathrm{km}$, and $10.9 \mathrm{~W}^{-1} \mathrm{~km}^{-1}$, respectively. A $1.6-\mathrm{nm}$ bandpass tunable optical filter at the output of NOLM1 is used to suppress the control signal. The FWHM pulsewidth of the converted pulse at $1545.6 \mathrm{~nm}$ is $3 \mathrm{ps}$. Then, the $10-\mathrm{Gb} / \mathrm{s}$ converted signal is passively multiplexed up to $80 \mathrm{~Gb} / \mathrm{s}$ using a fiber interleaver. After the $80-\mathrm{Gb} / \mathrm{s}$ OTDM signal is amplified in the SOA, NOLM2 is used to demultiplex the $80-\mathrm{Gb} / \mathrm{s}$ OTDM signal to a $10-\mathrm{Gb} / \mathrm{s}$ signal, and the control pulse is also obtained from the EFRL. NOLM2 consists of 3-km common DSF with zero dispersion wavelength of $1555 \mathrm{~nm}$, dispersion slope of $0.06 \mathrm{ps} / \mathrm{nm}^{2} / \mathrm{km}$, and nonlinear coefficient of $2.6 \mathrm{~W}^{-1} \mathrm{~km}^{-1}$.

Fig. 18 shows typical eye diagrams. Fig. 18(a) is the back-to-back eye diagram at $10 \mathrm{~Gb} / \mathrm{s}$. Fig. 18(b) is the eye diagram after wavelength conversion in NOLM1 at $10 \mathrm{~Gb} / \mathrm{s}$; a very good eye diagram is obtained. Fig. 18(c) is the multiplexed signal at $80 \mathrm{~Gb} / \mathrm{s}$ before the SOA. Fig. 18(d) is the amplified signal after the SOA for an input power of $-14 \mathrm{dBm}$ and after the TOF; there is no obvious difference between Fig. 18(c) and (d). Fig. 18(e) is the demultiplexed signal at $10 \mathrm{~Gb} / \mathrm{s}$, and a good eye diagram is obtained.

Fig. 19 shows BER performance. The penalty for the $80-\mathrm{Gb} / \mathrm{s}$ OTDM signal after demultiplexing to $10 \mathrm{~Gb} / \mathrm{s}$ without the SOA, compared to the $10-\mathrm{Gb} / \mathrm{s}$ converted signal, is $3 \mathrm{~dB}$. When the
80-Gb/s OTDM signal is amplified in the SOA with an input power of $-14 \mathrm{dBm}$ and demultiplexed in the NOLM2, the penalty at $10^{-9}$, compared to the $10-\mathrm{Gb} / \mathrm{s}$ converted signal, is $4.3 \mathrm{~dB}$. The added penalty after the signal is amplified in the SOA is $1.3 \mathrm{~dB}$; the added penalty is caused by SNR degradation after amplification in the SOA and by nonperfect filtering of the TOF.

Fig. 20(a) shows the optical spectra for the $80-\mathrm{Gb} / \mathrm{s}$ OTDM signal when the input power into the SOA is $-5 \mathrm{dBm}$. In order to compare with a 10-Gb/s RZ signal, the optical spectra for the 10-Gb/s RZ signal are also shown in Fig. 20(b) and the input power into the $\mathrm{SOA}$ is also $-5 \mathrm{dBm}$. Fig. 21 shows the shift in wavelength of the peak power as a function of the input power. It is clear that the shift in peak power is reduced for the 80-Gb/s OTDM signal. Because the duty cycle of RZ signals is very small, as shown in Fig. 10, the peak power is very large. The large peak power will lead to strong SPM in the SOA, and then the center wavelength of the signal after amplification in the SOA will be shifted to a very long wavelength. Therefore, the IPDR becomes very small when the transparent wavelength of the TOF after the SOA is kept fixed. For the $80-\mathrm{Gb} / \mathrm{s}$ OTDM, the peak power is small because the duty cycle is enhanced; therefore, the shift in wavelength of the peak power will be reduced. Furthermore, because the pulsewidth of the OTDM signal is smaller than the carrier lifetime, after amplification in the SOA, the pattern effect will be small, not like an NRZ signal.

Fig. 22 shows the power penalty as a function of the input optical power to the SOA. Keeping the transparent wavelength of the TOF fixed, the IPDR at 2-dB penalty is $10 \mathrm{~dB}$. Comparing with the $10-\mathrm{Gb} / \mathrm{s}$ RZ signal and 10-Gb/s NRZ signal, the IPDR at 2-dB penalty is increased to $4 \mathrm{~dB}$ and $2.5 \mathrm{~dB}$, respectively. Although the shift in wavelength of the peak power is reduced when the high-speed OTDM signal is amplified in the SOA, there is still some small change of the peak power as shown in Fig. 21. Therefore, it is necessary to shift the transparent wavelength of the TOF in order to obtain a very large IPDR. By shifting the TOF after the SOA, the IPDR is increased and the IPDR at 3-dB penalty is larger than $26 \mathrm{~dB}$; in addition, 


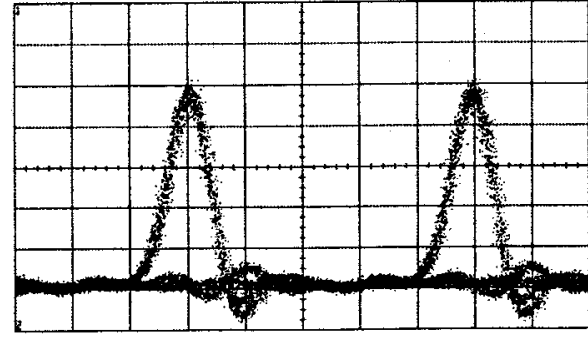

(a)

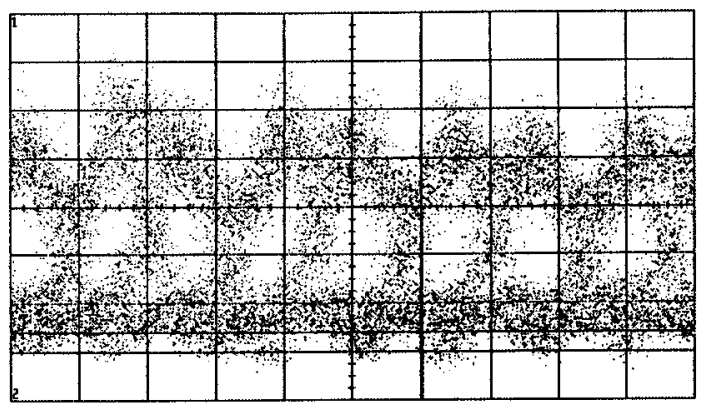

(c)

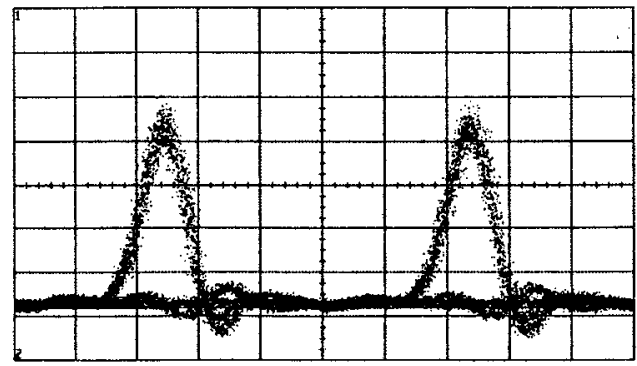

(b)

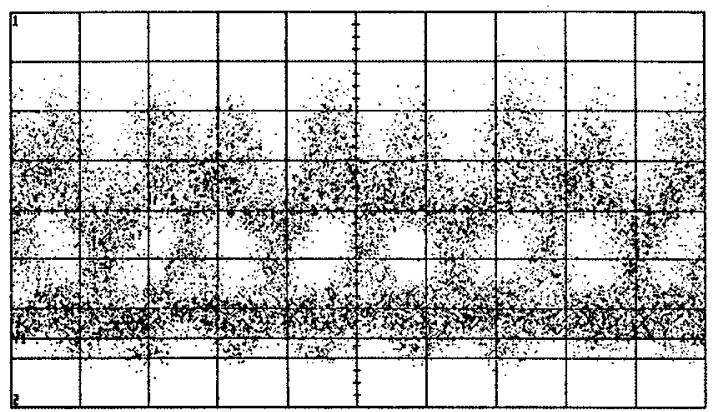

(d)

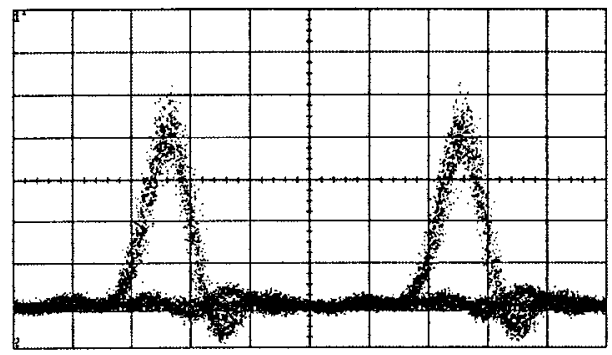

(e)

Fig. 18. Eye diagrams. (a) Back-to-back. (b) After wavelength conversion in NOLM1. (c) Input signal of 80-Gb/s OTDM. (d) 80-Gb/s OTDM after the SOA with input power of $-14 \mathrm{dBm}$ and the TOF. (e) After demultiplexing in NOLM2. (a), (b), and (e) are measured by a 32-GHz photodiode and shown in 20 ps/div. (c) and (d) are measured by a 50-GHz photodiode and shown in $10 \mathrm{ps} / \mathrm{div}$.

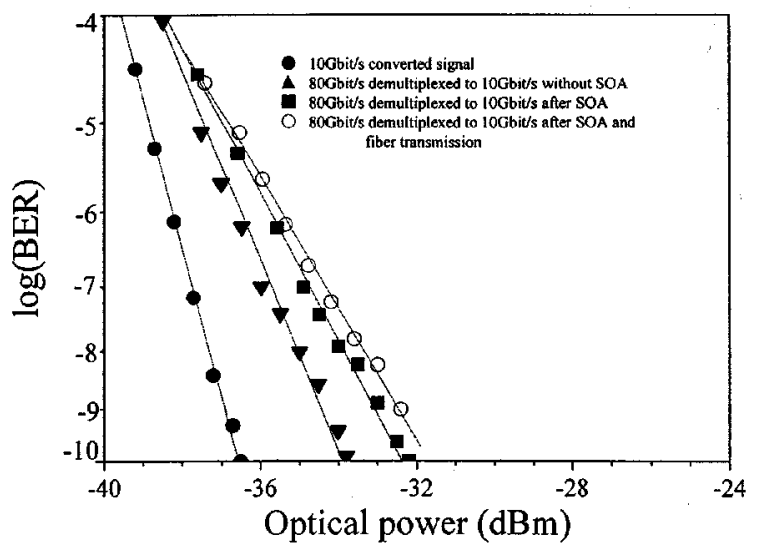

Fig. 19. BER performance.

there is error-free operation even when the input power to the SOA is as high as $0 \mathrm{dBm}$.

The multiplexed signal at $80 \mathrm{~Gb} / \mathrm{s}$ is launched into $44 \mathrm{~km}$ of conventional single mode fiber (SMF), passively dispersion compensated by 7-km wide-band dispersion compensating fiber (DCF). The total loss of the SMF and DCF is $12 \mathrm{~dB}$, the input power into the SMF is $-2 \mathrm{dBm}$, and the loss of the fibers is compensated by the SOA gain. BER performance is also shown in Fig. 19. Comparing the $80-\mathrm{Gb} / \mathrm{s}$ OTDM signal at $1545.6 \mathrm{~nm}$ before and after transmission, the penalty is seen to be small-approximately $0.5 \mathrm{~dB}$.

\section{DISCUSSION}

We have demonstrated that IPDR for $10-\mathrm{Gb} / \mathrm{s}$ RZ, $10-\mathrm{Gb} / \mathrm{s}$ NRZ, and $80-\mathrm{Gb} / \mathrm{s}$ OTDM signals can be improved by shifting the transparent wavelength of the TOF in the case of singe-channel input. Considering multiple-channel input, when the input signal of each channel is large enough-for example, larger than $-10 \mathrm{dBm}$ - there will be strong cross-gain modulation (XGM) when the wavelength division multiplexing (WDM) signals are amplified by the SOA, and crosstalk between different channels will be generated. The larger the input power of each channel, the larger the crosstalk. However, 


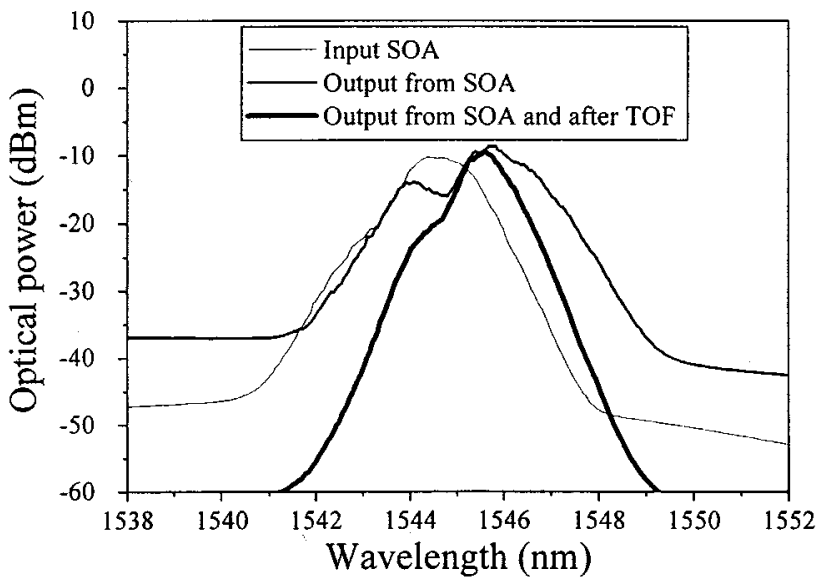

(a)

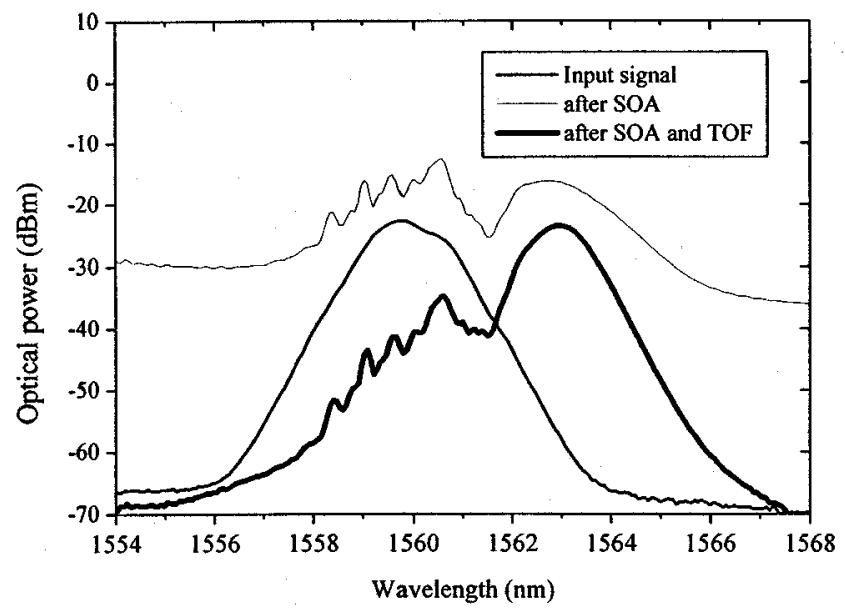

(b)

Fig. 20. Optical spectra for the input power into the SOA of $-5 \mathrm{dBm}$. (a) $80-\mathrm{Gb} / \mathrm{s}$ OTDM signal. (b) 10-Gb/s RZ signal.

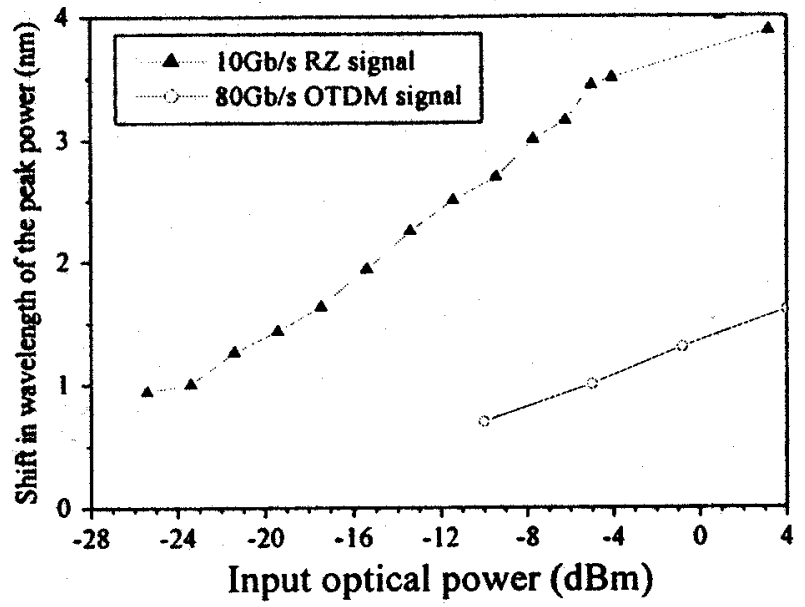

Fig. 21. Shift in wavelength of the peak power as a function of input optical power.

the crosstalk cannot be eliminated by shifting the transparent wavelength of the TOF; therefore, the IPDR cannot be improved. For amplifying WDM signals in SOAs, we believe that holding light injection is a suitable method to improve the IPDR of each channel; the crosstalk of different channels caused by

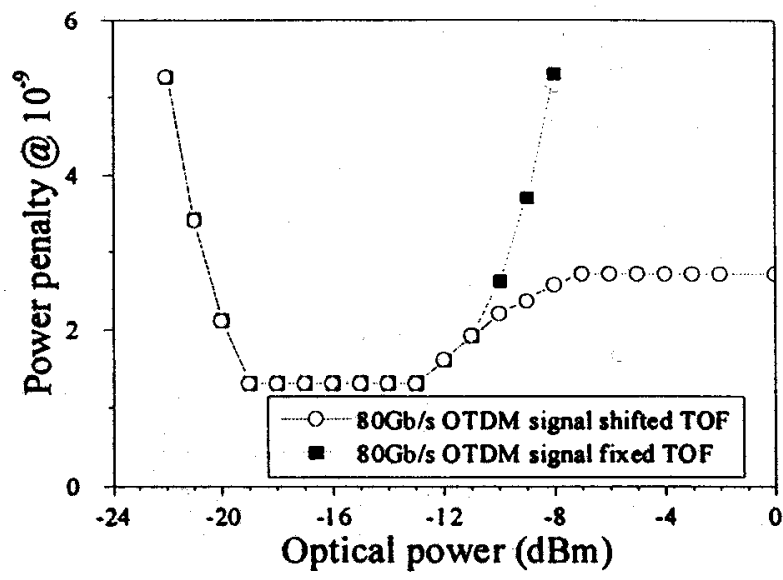

Fig. 22. Power penalty as a function of input optical power to the SOA.

XGM will be reduced because of the presence of strong holding light [6], [12]. However, the gain of each channel will also be reduced because the power of the holding light is always larger than the power of each channel.

\section{CONCLUSION}

Gain-saturation-induced SPM leads to pulse distortion when the signals are amplified in an SOA. We have experimentally demonstrated that shifting the transparent wavelength of the TOF is a very effective method for short pulse recovery and IPDR improvement for both RZ and NRZ signals.

The short pulse can be recovered or broadened by shifting the TOF, even if the short pulse is only $2-3$ ps long. When the transparent wavelength of the TOF is shifted to a longer wavelength, the pulse is recovered. When the transparent wavelength is shifted to the input signal wavelength, the pulse becomes broadened to approximately $25 \mathrm{ps}$, mainly determined by the carrier lifetime.

For 10-Gb/s RZ signals, because the optical spectrum of the leading edge of the " 1 "s is fully shifted to a longer wavelength and the falling edge of the " 1 "s and "0"s will remain at the original wavelength, the leading edge of " 1 "s can be obtained by shifting the TOF. Thus, the transparent wavelength of the TOF is shifted to a longer wavelength. Keeping the center wavelength of the TOF fixed, the IPDR at 2-dB power penalty is $6 \mathrm{~dB}$. However, shifting the TOF to a long wavelength, the IPDR at 2-dB penalty becomes larger than $32 \mathrm{~dB}$.

For 10-Gb/s NRZ signals, the optical spectrum is broadened to both the red and blue side, and the red-shifted part of the spectrum is larger than the blue-shifted part. The TOF is used to reduce the red-shifted part stemming from the gain-saturation-caused SPM; therefore, the transparent wavelength of the TOF is shifted to a shorter wavelength. Because the blue-shifted part of the spectrum caused by SPM cannot be suppressed, the pattern effect can not be eliminated fully. However, even though the blue-shifted part cannot be eliminated, the IPDR is strongly improved. When the transparent wavelength of the TOF is fixed, the IPDR at 2-dB power penalty is $7.5 \mathrm{~dB}$; however, when the TOF is shifted, the IPDR at 2-dB penalty is $16.5 \mathrm{~dB}$.

80-Gb/s OTDM signal amplification in the SOA has been demonstrated for the first time. For $80-\mathrm{Gb} / \mathrm{s}$ OTDM signals 
having the same average power and pulsewidth as the $10-\mathrm{Gb} / \mathrm{s}$ RZ signals, because the peak power of the signal is reduced, the shift in wavelength of the peak power will also be reduced. Furthermore, because the pulsewidth of the OTDM signal is smaller than the carrier lifetime, after amplification in the SOA, the pattern effect will be small in contrast to an NRZ signal; therefore, the IPDR is increased. The IPDR at $2-\mathrm{dB}$ penalty is $10 \mathrm{~dB}$. Keeping the transparent wavelength of the TOF fixed, and compared with a $10-\mathrm{Gb} / \mathrm{s}$ RZ and $10-\mathrm{Gb} / \mathrm{s}$ NRZ signals, the IPDR at $2-\mathrm{dB}$ penalty is increased by 4 and $2.5 \mathrm{~dB}$, respectively. However, although the shift in wavelength of the peak power is reduced when the high-speed OTDM signal is amplified in the SOA, there is still some change of the peak power. Therefore, it is necessary to shift the transparent wavelength of the TOF to obtain a much larger IPDR. Shifting the TOF, the IPDR is increased and the IPDR at 3-dB penalty becomes larger than $26 \mathrm{~dB}$; there is error-free operation even when the input power to the SOA is as high as $0 \mathrm{dBm}$.

\section{ACKNOWLEDGMENT}

The authors would like to thank Alcatel for providing the SOA, Lucent Technologies Denmark for providing the HNL-DSF, and Dr. K. Kojima for his encouragement and help.

\section{REFERENCES}

[1] G. P. Agrawal and N. A. Olsson, "Self-phase modulation and spectral broadening of optical pulses in semiconductor laser amplifiers," IEEE J. Quantum Electron., vol. 25, pp. 2297-2306, Nov. 1989.

[2] T. Fjelde, D. Wolfson, and A. Kloch, "Influence of RZ and NRZ signal format on the high-speed performance of gain-clamped semiconductor optical amplifiers," in OFC'2000, THF5.

[3] K. Inoue, "Optical filtering technique to suppress waveform distortion induced in a gain-saturated semiconductor optical amplifier," Electron. Lett., vol. 33, pp. 885-886, May 8, 1997.

[4] A. Elrefaie and C. Lin, "Performance degradations of multigigabit-persecond NRZ/RZ lightwave systems due to gain saturation in travelling-wave semiconductor optical amplifiers," IEEE Photon. Technol. Lett., vol. 1, pp. 300-303, Oct. 1989.

[5] D. Mahgerefteh, P. Cho, J. Goldhar, and G. L. Burdge, "Technique for suppression of pattern dependence in a semiconductor-optical-amplifier wavelength converter," IEEE Photon. Technol. Lett., vol. 9, pp. 1583-1585, Dec. 1997.

[6] J. Yu, A. Buxens, A. Clausen, and P. Jeppesen, "16 × 10 Gb/s WDM bi-directional gating in a semiconductor optical amplifier for optical cross connects exploiting network connection symmetry," IEEE Photon. Technol. Lett., vol. 12, pp. 702-704, June 2000.

[7] J. J. E. Reid, L. Cucala, M. Settembre, R. C. J. Smets, M. Ferreira, and H. F. Haunstein, "An international field trial at $1.3 \mu \mathrm{m}$ using an $800 \mathrm{~km}$ cascade of semiconductor optical amplifiers," in Proc. ECOC, vol. 1, Madrid, Spain, Sept. 1998, pp. 567-568.

[8] Y. Sun, A. K. Srivastava, S. Banerjee, J. W. Sulhoff, R. Pan, K. Kantor, R. M. Jopson, and A. R. Chraplyvy, "Error-free transmission of $32 \times$ $2.5 \mathrm{~Gb} / \mathrm{s}$ DWDM channels over $125 \mathrm{~km}$ using cascaded in-line semiconductor optical amplifier," Electron. Lett., vol. 35, pp. 1863-1865, Oct. 14, 1999.
[9] L. H. Spiekman, J. M. Wiesenfeld, A. H. Gnauck, L. D. Garrett, G. N. van den Hoven, T. van Dongen, M. J. H. Sander-Jochem, and J. J. M. Binsma, "Transmission of 8 DWDM channels at $20 \mathrm{~Gb} / \mathrm{s}$ over $160 \mathrm{~km}$ of standard fiber using a cascade of semiconductor optical amplifiers," IEEE Photon. Technol. Lett., vol. 12, pp. 717-719, June 2000.

[10] J. Yu, A. Clausen, H. N. Poulsen, X. Zheng, C. Peucheret, and P. Jeppesen, "40Gb/s wavelength converison in cascade of SOA and NOLM and demonstration of extinction ratio improvement," Electron. Lett., vol. 36, pp. 963-964, May 25, 2000.

[11] J. Yu, P. Jeppesen, and S. N. Knudsen, "80Gbit/s pulsewidth-maintained wavelength conversion based on a HNL DSF-NOLM including transmission over 80km of conventional SMF," Electron. Lett., vol. 37, pp. 577-579, Aprl 26, 2001.

[12] J. Yu and P. Jeppesen, "Improvement of cascaded semiconductor optical amplifier gates by using holding light injection," J. Lightwave Technol., vol. 19, pp. 614-623, May 2001.

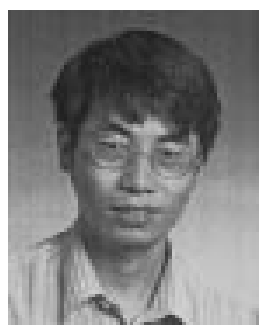

Jianjun Yu was born in Hunan, China, 1968. He received the B.S. degree in optics from Xiangtan University, Hunan, in 1990 and the M.E. and Ph.D. degrees in optical communications from Beijing University of Posts and Telecommunications, Beijing, China, in 1996 and 1999, respectively.

He joined Research Center COM, Technical University of Denmark, Lyngby, as a Postdoctoral Fellow in June 1999, where he researched high-speed optical communication systems and networks. In December 1999, he became an Assistant Research Professor. In February 2001, he joined Agere Systems, Murray Hill, NJ. His current research interests are the generation of WDM short-pulse optical source fiber nonlinear in high-speed WDM/OTDM optical communication systems, all-optical signal procession, wavelength conversion, and the application of semiconductor optical amplifier in optical networks.

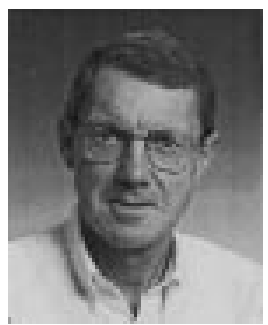

Palle Jeppesen (M'69) was born in Vordingborg, Denmark on August 6, 1941. He received the M.Sc., Ph.D., and Dr.Sc. degrees in electrical engineering from Technical University of Denmark, Lyngby, in 1967, 1970, and 1978, respectively.

From 1968 to 1969 , he was a Research Associate at Cornell University, Ithaca, NY, and from 1969 to 1970 , a Project Engineer at Cayuga Associates, Ithaca, NY; at both places, he did research in the field of GaAs Gunn effect microwave oscillators. From 1970 to 1998, he was an Assistant, Associate, Research, and Full Professor at EMI, Technical University of Denmark, first in microwave electronics, and since 1974, in optical communications. At EMI, he was Head of Optogroup from 1974 to 1988, and Head of the Center for Broadband Telecommunications from 1988 to 1998. From 1982 to 1984, he also worked as part-time Manager of R\&D at NKT Elektronik, now Draka Denmark Optical Cable, Lucent Technologies Denmark, and Tellabs Denmark. From 1995 to 1998 , he coordinated the participation of the Technical University of Denmark in the EU ACTS project METON (METropolitan Optical Network). Since 1999, he has been Professor in optical communications at Research Center COM, where he is heading the Systems Competence Area. His research interests include high-speed WDM optical communication systems, in particular, dispersion maps and WDM devices. 